\title{
A comparison of lodgepole and spruce needle chemistry impacts on terrestrial biogeochemical processes during isolated decomposition
}

\author{
Laura T Leonard $^{1}$, Kristin Mikkelson ${ }^{1}$, Zhao Hao ${ }^{2}$, Eoin L Brodie ${ }^{2}$, Kenneth H Williams ${ }^{2,3}$, Jonathan 0 Sharp ${ }^{\text {Corresp. }}$ \\ 1 Department of Civil and Environmental Engineering, Colorado School of Mines, Golden, Colorado, United States \\ 2 Lawrence Berkeley National Laboratory, Berkeley, California, United States \\ 3 Rocky Mountain Biological Laboratory, Crested Butte, CO, USA \\ Corresponding Author: Jonathan O Sharp \\ Email address: jsharp@mines.edu
}

This study investigates the isolated decomposition of spruce and lodgepole conifer needles to enhance our understanding of how needle litter impacts near-surface terrestrial biogeochemical processes. Harvested needles were exported to a subalpine meadow to enable a discrete analysis of the decomposition processes over two years. Initial chemistry revealed the lodgepole needles to be less recalcitrant with a lower carbon to nitrogen $(C: N)$ ratio. Total $\mathrm{C}$ and $\mathrm{N}$ fundamentally shifted within needle species, over time with decreased $\mathrm{C}: \mathrm{N}$ ratios for spruce and increased ratios for lodgepole. Differences in chemistry correlated with $\mathrm{CO}_{2}$ production and soil microbial communities. The most pronounced trends were associated with lodgepole needles in comparison to the spruce and needlefree controls. Increased organic carbon and nitrogen concentrations associated with needle presence in soil extractions further corroborate the results with clear biogeochemical signatures in association with needle chemistry. Interestingly, no clear differentiation was observed as a function of bark beetle impacted spruce needles versus those derived from healthy spruce trees despite initial differences in needle chemistry. These results reveal that the inherent chemistry associated with tree species has a greater impact on soil biogeochemical signatures during isolated needle decomposition. By extension, biogeochemical shifts associated with spruce beetle infestation are likely driven more so by other changes such as the cessation of rhizospheric processes than by needle litter decomposition. 


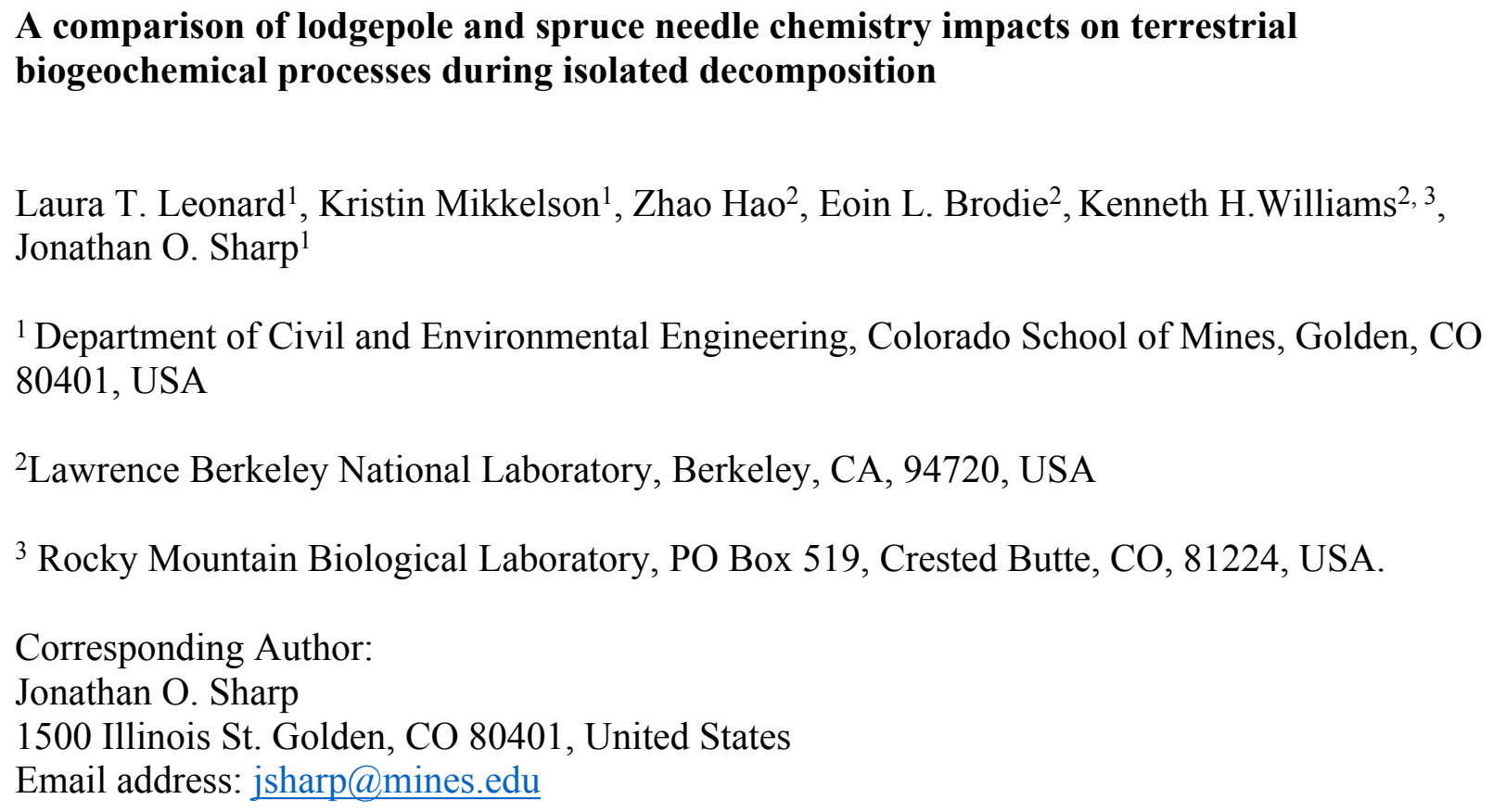




\section{Abstract}

31 This study investigates the isolated decomposition of spruce and lodgepole conifer needles to

32 enhance our understanding of how needle litter impacts near-surface terrestrial biogeochemical

33 processes. Harvested needles were exported to a subalpine meadow to enable a discrete analysis

34 of the decomposition processes over two years. Initial chemistry revealed the lodgepole needles

35 to be less recalcitrant with a lower carbon to nitrogen $(\mathrm{C}: \mathrm{N})$ ratio. Total $\mathrm{C}$ and $\mathrm{N}$ fundamentally

36 shifted within needle species, over time with decreased $\mathrm{C}: \mathrm{N}$ ratios for spruce and increased ratios

37 for lodgepole. Differences in chemistry correlated with $\mathrm{CO}_{2}$ production and soil microbial

38 communities. The most pronounced trends were associated with lodgepole needles in

39 comparison to the spruce and needle-free controls. Increased organic carbon and nitrogen

40 concentrations associated with needle presence in soil extractions further corroborate the results

41 with clear biogeochemical signatures in association with needle chemistry. Interestingly, no clear

42 differentiation was observed as a function of bark beetle impacted spruce needles versus those

43 derived from healthy spruce trees despite initial differences in needle chemistry. These results

44 reveal that the inherent chemistry associated with tree species has a greater impact on soil

45 biogeochemical signatures during isolated needle decomposition. By extension, biogeochemical

46 shifts associated with spruce beetle infestation are likely driven more so by other changes such as

47 the cessation of rhizospheric processes than by needle litter decomposition.

\section{Introduction}


Forest litter decomposition alters surrounding soil by influencing mechanisms that include terrestrial carbon (C) and nitrogen (N) cycling (Šantrůčková, Krištůfková, and Vaněk, 2006; Hicks Pries et al., 2017). Several studies have looked further into these contributions to soil biogeochemistry; however, the observed impacts of decomposition on soil biogeochemistry differ between studies as a function of forest structure and tree mortality levels that fluctuate with time (Negrón and Cain, 2018; Fraterrigo, Ream, and Knoepp, 2018). Recent bark beetle outbreaks in association with climate change have resulted in increased tree mortality within forests and pulsed litterfall that collectively result in short and long-term impacts to the forest ecosystem (Edburg et al., 2012; Mikkelson et al., 2013). A discrete analysis of litter decomposition could help us better understand its relative contribution to broader processes such as why certain forests reveal different $\mathrm{C}$ and $\mathrm{N}$ signatures from others.

forest floor that adds additional organic inputs to the litter decomposition process (Edburg et al., 2012). In concert, reduced canopy cover causes shifts in tree hydrologic processes such as canopy interception and evapotranspiration (Mikkelson et al., 2013; Bearup et al., 2014) further altering the decomposition process with changes to soil temperature and moisture levels. This litter decomposition is coupled to the cessation of rhizospheric processes and collectively results in tree-scale biogeochemical shifts in net soil respiration (Brouillard et al., 2017), soil nutrient levels (Clow et al., 2011; Cigan et al., 2015), and soil carbon concentration and character (Brouillard et al., 2017; Fraterrigo, Ream \& Knoepp, 2018). However, we do not fully understand how needle decomposition versus other variables such as cessation of rhizodeposits and reduced canopy alters the magnitude, character and timing of the biogeochemical response. 
75 endemic bark beetle species are prevailing at higher magnitudes globally. Increased outbreaks in

76 conifer forests have been documented in Europe, Canada, and the United States causing concern

77 for forest aesthetics and economics as well as altered ecosystem and watershed function

78 ("Mountain pine beetle | Natural Resources Canada," 2013; "Bark Beetles - US Forest Service

79 Research \& Development Bark Beetles,” 2019; Hlásny et al., 2019).

80 To this end, we designed a study to isolate spruce and lodgepole needle litter from the

81 complexity of tree-scale processes. We hypothesized that the isolated decomposition of needles

82 containing different organic carbon and nitrogen signatures would impart unique soil

83 biogeochemical responses. Soil respiration, C, N, porewater composition, and microbial ecology

84 were then compared as a function of tree species and bark beetle impact over two years of

85 decomposition in a subalpine meadow environment (3,170 meters above sea level) in Crested

86 Butte, Colorado. Recently, mountain pine beetle (Dendroctonus ponderosae) outbreaks were

87 cause for concern in Colorado with peak lodgepole pine mortality occurring in 2008 (2017

88 Report on the health of Colorado's forests, 2018). Spruce beetle (Dendroctonus rufipennis)

89 infestation has intensified since 2011. This approach allowed us to decouple the effects of

90 varying litter decomposition from the tree canopy and root network to better understand selective

91 pressures exerted by needle decomposition on tree-scale biogeochemical processes and their

92 relevance to ecosystem disruption.

93

94 2. Materials \& Methods

952.1 Needle sample collection

96 Needle litter samples were collected in August 2016 from separate forests containing two

97 tree species, lodgepole pine (Pinus contorta) and Engelmann spruce (Picea engelmannii). 
98 Throughout the paper these collected needles will be referred to as "harvested needles". The

99 lodgepole pine needles were collected in White River National Forest near Frisco, Colorado

$100\left(39.54^{\circ} \mathrm{N}, 106.15^{\circ} \mathrm{W}\right.$, elevation 3,050 meters). The forest is mostly lodgepole pine and

101 experienced mountain pine beetle infestation between 2007 and 2008 (Brouillard et al., 2017).

102 The soil type of this location is a Leighcan family- Cryaquolls complex with metamorphic gneiss

103 bedrock (Soil Survey Staff; U.S. Geological Survey, 2005). This site was chosen for its large

104 area of lodgepole pine trees that have not been affected by anthropogenic activities. Litter was

105 collected under lodgepole trees that had naturally senesced. Throughout the paper, these needles

106 will be referred to as "lodgepole."

107 Spruce needles were collected from Monarch Pass $\left(38.50^{\circ} \mathrm{N}, 106.33^{\circ} \mathrm{W}\right.$, elevation

1083,440 meters) located in central Colorado between Gunnison and Chaffee county where the

109 forest is predominantly Engelmann spruce. The bedrock of this location is granitic igneous

110 intrusive (U.S. Geological Survey, 2005). The soil type of this location is not available. This site

111 was chosen for its abundance of spruce trees with active spruce beetle infestation that intensified

112 in the area during 2015 (“2015 Report on the Health of Colorado's Forests: 15 Years of

113 Change”, 2016). Visual observations included beetle boreholes, intensive sap release from pitch

114 tubes along with live larvae and adult beetles underneath the outer bark layers. Within months of

115 observing beetle infestation, the impacted spruce needles turned red, further confirming spruce

116 beetle infestation. By August 2016 the majority of needles had fallen from the impacted trees and

117 were then collected from both impacted and naturally senesced spruce trees from this forest. The

118 needles collected under the impacted trees are referred to as "impacted" spruce needles

119 throughout this paper and the needles collected under non-impacted naturally senesced spruce

120 trees will be referred to as "healthy" spruce needles. 
122 dry until deployment. The dry needles were sieved using a Tyler Equivalent $10 \mathrm{mesh}, 1.7 \mathrm{~mm}$ to

123 homogenize the collected litter from each respective sample type and remove rocks and dirt. The

124 sieved needles were then weighed into 250 gram subsets based on the three needle sample types

125 and aliquoted for deployment at the study site described below. All litter composition results are

126 presented based on air-dried weight.

127 2.2 Study site and needle deployment

128 The experimental plot used in this study is located in Crested Butte, Colorado. The plot is

129 located within the subalpine region of the Washington Gulch drainage into the East River

130 watershed located at $38.95^{\circ} \mathrm{N}, 107.03^{\circ} \mathrm{W}$, with an elevation of 3,170 meters and a northeast

131 aspect and average slope of $9-12^{\circ}$. The plot is located in an open meadow to ensure isolation

132 from surrounding tree canopies and roots. The subalpine meadow soil type is classified as a

133 mixture of Tilton sandy loam and Cryaquolls and Histosols with sedimentary clastic Mancos

134 shale bedrock (Soil Survey Staff; U.S. Geological Survey, 2005). Conifer tree stands are within

135 approximately $300 \mathrm{~m}$ of the experimental plot.

136 Climate data was collected from the nearest snow telemetry (SNOTEL) weather station

137 on Mt. Crested Butte (38.89 $\left.{ }^{\circ} \mathrm{N}, 106.95^{\circ} \mathrm{W}\right)$ at 3,100 meters elevation (site number 380). Mean

138 annual precipitation over the study years of 2016-2018 averaged $65 \mathrm{~cm}$, most of which falls as

139 snow starting in September/October and continues through May. The average daily temperatures

140 recorded at the Butte SNOTEL location were separated into the snow-free months of May-

141 September and snow-covered months of October-April. The temperatures averaged $11.6^{\circ} \mathrm{C}$ and -

$1421.1^{\circ} \mathrm{C}$, respectively. Hourly soil temperature was measured with unshielded microclimate

143 sensors buried on-site at 12cm soil depth. The mean soil temperatures recorded over 2016-2018 
144 were $12.6{ }^{\circ} \mathrm{C}$ during the months of May-September, and $1.4{ }^{\circ} \mathrm{C}$ during the months of October145 April.

146 Needles were deployed at the experimental plot in October 2016 in $25.4 \mathrm{~cm}$ diameter

147 white polyvinyl chloride (PVC) collars before winter snowfall. The collars were $18 \mathrm{~cm}$ in height

148 with a beveled edge at the end. Beveled end first, the collars were driven into the ground to leave

149 approximately $10 \mathrm{~cm}$ of the height above ground level. Foliage was raked and pulled out of the

150 ground to remove all native plants and roots. A total of $16 \mathrm{PVC}$ rings were inserted into the

151 ground to hold four sample types in quadruplicate. The plot matrix was established with

152 quadruplicate samples as follows: 4x250 grams of healthy spruce, 4x250 grams impacted spruce,

$1534 \times 250$ grams lodgepole and 4x needle-free controls (bare soil). Randomization of harvested

154 needle samples was achieved using R Studio to produce a 4x4 matrix with sample assignments.

155 A schematic of this field deployment grid with the randomized samples can be found in Figure

156 S1.

Soil Moisture's 1905L06 $15 \mathrm{~cm}$ lysimeters were installed in the middle of each ring with

158 a bentonite seal over the surface. The needles were placed on top of the soil surface and

159 surrounding the lysimeter. Each collar top was covered with deer netting and secured to

160 minimize interference from native animals. Onset HOBO Data Loggers soil moisture (S-SMD-

161 M005) and temperature (S-TMB-M006) probes were installed per manufacturer instructions at

$16212 \mathrm{~cm}$ depth within the sample grid to monitor soil moisture and temperature hourly.

163 While the needle deployment limited emergent plant growth, any new growth was

164 manually pulled out of the soil with as little disturbance as possible. Frequent monitoring of the

165 plots similarly ensured that bare soil control rings were free of emerging plant growth. In

166 October 2017, one quadruplicate ring from each of the four sample types was sacrificed for soil 
167 extractions. This reduced the number of sample replicates to three for subsequent samplings. In

168 addition, shaded controls were added in May of 2018 prior to any 2018 measurements with

169 randomized placement of three PVC rings on bare soil with two layers of permeable $50 \%$ black

170 mesh shade fabric secured over the rings to understand the impact of solar radiation (Fig. S1).

171 Biogeochemical attributes of needle decomposition were then measured with soil respiration,

172 porewater composition, and microbial analysis as a function of tree species and bark beetle

173 impact over two years of decomposition.

\subsection{Needle composition: Total carbon, nitrogen and FTIR analyses}

175 An initial subset of each harvested needle type (healthy spruce, impacted spruce, and

176 lodgepole) was used for compositional analysis at the start of the experiment. This same

177 compositional analysis was conducted on a subset of needles collected from each sample collar

178 two years later (October of 2018). Needles were set in a dark and dry location at room

179 temperature to air dry. Once air-dried, the needles were ground to a fine powder and submitted in

180 triplicate for total carbon and nitrogen analysis at Colorado State University's Ecocore facility

181 with the LECO TruSpec CN analyzer (LECO Corporation) and Fourier Transform Infrared

182 (FTIR) analysis at Lawrence Berkley National Laboratory. The FTIR spectrometer used was

183 equipped with an attenuated-total-reflection accessory (Nicolet IS50, Thermo Fisher Scientific

184 Inc). The sample was pressed down uniformly on the top surface of the crystal and the reflected

185 infrared signal from the sample was collected to a deuterated-triglycine sulfate detector. All

186 collected absorption spectra were further preprocessed for baseline correction and peak-by-peak

187 analysis was applied to quantify the concentration of each functional group which was linearly

188 correlated to the absorbance following Lambert-Beer's Law. 
190 of the harvested needles to determine the initial extractable carbon and nitrogen concentrations.

191 Measurements of extractable dissolved organic carbon (DOC), $\mathrm{UV}_{254}$, and total nitrogen (TN)

192 were conducted after equilibrating in deionized water following one hour of shaking in 1:8 solid

193 mass: liquid volume ratio. The extractions were filtered through $0.45 \mu \mathrm{m}$ s filters. Filtrate DOC

194 and TN were tested using a Shimadzu TOC-550A Total Organic Carbon Analyzer after

195 acidifying with hydrochloric acid. $\mathrm{UV}_{254}$ was measured using a DU 800 spectrophotometer.

196 Specific UV absorbance (SUVA) was calculated by normalizing the $U_{254}$ values with the

197 respective DOC concentrations in $\mathrm{mg} / \mathrm{L}$ for porewater samples and $\mathrm{mg} / \mathrm{g}$ for the soil and litter

198 extractions following Environmental Protection Agency Method 415.3 and (Eq. 1) (Potter \&

199 Wimsatt, 2009):

$$
\operatorname{SUVA}(\mathrm{L} / \mathrm{mg}-\mathrm{m})=\operatorname{UVA}\left(\mathrm{cm}^{-1}\right) / \mathrm{DOC}(\mathrm{mg} / \mathrm{L}) * 100 \mathrm{~cm} / \mathrm{m}
$$

201

202

203

204

205

206

207

208

209

210

211

\subsection{Gas flux analysis}

Gas flux measurements were conducted above each soil collar during the snow-free months for a total of eleven sampling events over two years. Data was collected over an approximate two-hour window that fell midday between 10AM and 3PM. The collar sampling sequence was randomized each time to account for temporal fluctuations in variables such as temperature and moisture. Gas flux measurements were conducted using a Picarro G2508 cavity ring-down spectroscopy analyzer capable of analyzing $\mathrm{CO}_{2}, \mathrm{CH}_{4}, \mathrm{NO}_{2}, \mathrm{NH}_{3}$ and $\mathrm{H}_{2} \mathrm{O}$.

Guaranteed spec ranges of the G2508 are 0.3-200 ppm $\mathrm{NO}_{2}, 1.5-12 \mathrm{ppm} \mathrm{CH}_{4}, 380-5000 \mathrm{ppm}$ $\mathrm{CO}_{2}, 0-300 \mathrm{ppb} \mathrm{NH}_{3}$, and 0-3\% $\mathrm{H}_{2} \mathrm{O}$. A closed system was implemented with two lengths of norprene tubing and an airtight PVC chamber to circulate the headspace for the duration of the sample period. One length of the tubing was attached to the Picarro gas inlet and the other was 
212 attached to the outlet. Each end of the tubing was then connected to an inlet and outlet valve in

213 the PVC chamber that was placed over the permanently deployed PVC collars. After steady state

214 was established by linear trends of production or removal, data collection was initiated for two

215 minutes. The Hutchinson \& Mosier method provided with the Picarro computer software was

216 used to compute a best fit for each gas trend to calculate the fluxes.

\subsection{Porewater and soil extraction analysis}

218 Porewater was collected from within each PVC collar after snowmelt in the spring and

219 high moisture events during early fall for a total of four collections over two years. Porewater

220 was collected from the lysimeters using a Luer-lok $50 \mathrm{~mL}$ vacuum syringe. The samples were

221 filtered to $0.45 \mu \mathrm{m}$ and frozen the same day of collection for storage at $-20{ }^{\circ} \mathrm{C}$ until analysis. The

222 samples were subsequently thawed for TN, DOC, and SUVA analyses as specified in Section 2232.3

Extractions were conducted with soil underlying the needles from single quadruplicate

225

226

227

228

229

230

231

232

233 collars sacrificed for each sample type in the Fall of 2017. The extractions were conducted according to the methods outlined in Section 2.3 except with a 2:9 solid mass: liquid weight ratio. Soil samples were collected from the upper surface horizon in contact with decomposed matter $(2-3 \mathrm{~cm})$ and mixed for a homogenized sample from which five subsamples were collected. Geochemical extractions were conducted with DI water following the methods of (Brouillard et al., 2017). Resulting filtrate at $0.45 \mu \mathrm{m}$ was analyzed for TN, DOC, and SUVA as described in Section 2.3. Ammonium concentrations were measured using the sodium salicylate method and absorbance at $650 \mathrm{~nm}$ with a DR 3900 Hach Spectrometer. Nitrite and nitrate were measured using an ICS-5000 ion chromatography analysis consisting of an ICS-5000 DC

Peer) reviewing PDF | (2020:02:45793:1:1:NEW 3 Jun 2020) 
234 Conductivity Detector, an ICS-5000 DP Isocratic Pump, and an AS-DV Autosampler. All soil

235 extraction results were normalized by air-dried weights.

2362.6 DNA extraction and preparation

237 Soil samples for DNA extractions were collected within each PVC collar for microbial

238 analysis at five time points over two years: August 2017, October 2017, May 2018, July 2018,

239 and October 2018 to align with the early, mid, and late-season snow-free months. Samples were

240 collected in the upper 1-2 cm soil layer under each representative needle type with sterilized

241 scoopulas. Homogenization was achieved by collecting a minimum of ten subsamples of soil

242 from the first $2 \mathrm{~cm}$ of the upper soil surface to fill a $2 \mathrm{~mL}$ test tube. This process was conducted

243 throughout the full collar surface area to completely represent the sample. Care was taken to

244 ensure samples were randomly collected across the soil surface and not biased towards the inside

245 or outside edges of the collar. The soil samples were then frozen for storage at $-20^{\circ} \mathrm{C}$ until

246 analysis. DNA was extracted from the samples using the ZymoBIOMICS DNA Miniprep kit

247 according to the manufacturer instructions using $0.25 \mathrm{~g}$ weighed out from each $2 \mathrm{~mL}$ sample tube.

$248 \quad 16 \mathrm{~S}$ and $18 \mathrm{~S}$ gene amplification was conducted using 5 Prime Hot MasterMix and a

249 primer set utilizing the 515-Y forward primer and 926R reverse primer (Parada, Needham \&

250 Fuhrman, 2016). An adapted forward primer was utilized with the addition of the M13 sequence

251 to allow sample barcoding during PCR (Caporaso et al., 2012; Stamps et al., 2016). Resulting

252 amplicons were purified and normalized to equimolar concentrations. The samples were then

253 concentrated using the $30 \mathrm{~K}$ ultra centrifugal Amicon filters. The final concentrations were

254 determined using the Qubit 2.0 fluorometric quantitation. The library was sent to the Duke

255 Center for Genomic and Computational Biology for Illumina MiSeq sequencing using V2 PE250 
256 chemistry. Raw sequence data has been deposited in the NCBI SRA database under SRA

257 accession number PRJNA605259.

$258 \quad 2.7$ Sequence processing

259 The resulting raw reads from sequencing were joined, quality filtered, clustered and had

260 chimeras removed using the DADA2 package (Callahan et al., 2016). Sequences were trimmed

261 to excise forward and reverse primer sequences in methods utilized by (Honeyman, Day \&

262 Spear, 2018) in which the first 40 nucleotides of the forward primer sequences and the last 20 of

263 the reverse primer were removed and then trimmed using a quality score of $2.18 \mathrm{~S}$ sequences

264 were analyzed separately from $16 \mathrm{~S}$ where the forward and reverse reads were combined by

265 concatenating the reads directly, despite the absence of an overhanging region of $18 \mathrm{~S}$ gene

266 sequenced by both the forward and reverse reads. Both $18 \mathrm{~S}$ and $16 \mathrm{~S}$ taxonomic assignments

267 were created using Silva v128 (Pruesse, Peplies \& Glöckner, 2012). Sequences for each sample

268 were filtered into either Eukaryota (18S) or Bacteria (16S). Chloroplasts and Mitochondria were

269 removed from all 16S sequences. After processing and quality filtering for the 16S genes,

270796,847 sequences were obtained across 69 samples with sequence depth ranging from 18 -

27119,498 sequences per sample and were rarefied to 5,638 sequences. The yield for $18 \mathrm{~S}$ sequences

272 with these primers was lower at 34,009 across 69 samples. Sequence depth ranged from 0 to

2732,950 sequences per sample and were rarefied to 200 sequences. All subsequent analysis except

274 differential abundance testing was based on the rarefied sequence tables.

275 All downstream analysis was conducted in R (v1.0.153), using the Phyloseq (v1.26.1)

276 (McMurdie \& Holmes, 2013), vegan (Oksanen et al., 2019), DESeq2 (Love, Huber \& Anders,

277 2014), and ampvis2 (Andersen et al., 2018) packages.

278 2.8 Statistical Analyses

Peer) reviewing PDF | (2020:02:45793:1:1:NEW 3 Jun 2020) 
280 Friedman test followed by the post hoc Wilcoxon test. Due to low sample sizes $(n=3)$ no

281 significant values were returned with these methods for the various geochemical tests conducted.

282 Spearman and Pearson tests were used to assess nonlinear and linear correlations between gas

283 flux and soil parameters. For the DNA sequence results, beta diversity was assessed using both

284 weighted and unweighted UniFrac distance matrices and significant clustering was determined

285 using the Adonis test. Differential abundance comparisons were conducted using DESeq2. In all

286 statistical tests, p-values less than 0.05 were considered significant.

\section{3. Results}

\subsection{Chemical composition of harvested and decomposed needles}

289 The initial chemical differences between needle types were determined with the

290 harvested needles prior to deployment (Fig. 1A,B). Clear differences in needle chemistry were

291 apparent. Harvested naturally senesced lodgepole needles contained the highest percentages of

292 total $\mathrm{C}$ and $\mathrm{N}$ in contrast to both spruce needle types. The harvested impacted (beetle-killed)

293 spruce needles were higher in total C and N than the healthy (naturally senesced) spruce needles

294 (Table S1). Impacted spruce exhibited a higher carbon to nitrogen $(\mathrm{C}: \mathrm{N})$ ratio in contrast to the

295 lower ratios between the lodgepole and healthy spruce needles (Fig. 1A). After two years of

296 decomposition, the differences between needle types were amplified with transitions as a

297 function of tree species (Fig. 1A,C). The average total carbon content decreased for all

298 decomposed needle types, however with high variability in the healthy spruce (39\% \pm 15$)$ (Table

299 S1). Interestingly, the average total nitrogen content increased in both impacted and healthy

300 spruce needles while lodgepole decreased in total nitrogen, again with high variability in healthy

301 spruce $(0.9 \% \pm 0.3)$ (Table $\mathrm{S} 1)$. Overall, there was a decrease in the average C:N ratio for both 
302 impacted and healthy spruce needles and an increase in lodgepole after two years of

303 decomposition (Fig. 1A).

$304 \quad$ FTIR analysis further confirmed compositional differences between initial harvested

305 needle types based on several peak absorbances (Fig. 1B). Notably, the spectra for the 2016

306 lodgepole needles exhibited clear differences from the spruce needles in litter quality based on

307 integrated peak areas at ether linkages $\left(1150 \mathrm{~cm}^{-1}\right)$, aromatics $\left(1510 \mathrm{~cm}^{-1}\right)$, amides $\left(1600 \mathrm{~cm}^{-1}\right)$,

308 and carbonyls $\left(1720 \mathrm{~cm}^{-1}\right)$. Previous studies have associated lignin content with the aromatics

309 peak and cellulose content with ether linkages (Pandey \& Pitman, 2003; Özgenç, Durmaz \&

310 Kuştaş, 2017). By applying the same inferences as these past studies, differences in the aromatic

311 and ether linkage peak areas indicate lower recalcitrance, or lignin quantity and more labile

312 carbon such as cellulose in lodgepole needles when compared to the spruce needles (Fig. 2A,B).

313 Impacted versus healthy spruce FTIR spectra, while more similar, exhibited differences

314 in aromatics, amides, and carbonyl peak areas. After two years of decomposition, integrated peak

315 analysis revealed a shift between the 2016 harvested needles and the 2018 decomposed needles

316 (Fig. 2). The observed differences between lodgepole and spruce needles in the four major

317 functional groups were maintained two years after decomposition. Specifically, lodgepole

318 needles maintained a more labile and less recalcitrant litter quality in contrast to both impacted

319 and healthy spruce needles. (Fig. 2A,B). Further, the ratio of ether linkages to aromatics

$320\left(1150: 1510 \mathrm{~cm}^{-1}\right)$ over two years of decomposition revealed a significant increase in lodgepole

321 compared to the lesser increases in the healthy and impacted spruce needles (Fig. 2E, Table S2).

322 DI water extractions with the harvested needles revealed water extractable constituents

323 differed between all needle types in which impacted spruce needles released the highest

324 extractable carbon in contrast to lower values for lodgepole and healthy spruce needles. The total 
325 extractable nitrogen was highest in association with spruce needles in contrast to lodgepole with

326 similar values between impacted and healthy spruce. As determined by specific UV absorbance,

327 more aromatic organic carbon was extracted from the healthy spruce and lodgepole in contrast to

328 the impacted spruce (Table 1).

3293.2 Gas flux from needle and control deployments

$330 \quad$ Needle presence and seasonality impacted soil gas flux over the period of the study (Fig.

$3313 \mathrm{~A}, \mathrm{~B})$. The presence of decomposing needles increased $\mathrm{CO}_{2}$ production in contrast to the

332 controls. Throughout all sampling events, the needle-free controls produced the lowest average

$333 \mathrm{CO}_{2}$ flux while lodgepole needle decomposition released the most $\mathrm{CO}_{2}$. The shaded control

334 added in 2018 produced $\mathrm{CO}_{2}$ magnitudes that aligned or were less than the exposed control,

335 confirming shading effects from the needles did not drive the differences observed in the needle 336 samples (Fig. 3A,B).

337 Seasonal trends were also observed during sampling events. Gas flux measurements were

338 influenced by soil moisture as evidenced by peaks in $\mathrm{CO}_{2}$ production that followed peaks in soil

339 moisture (Fig. 3). This observed relationship between $\mathrm{CO}_{2}$ production and soil moisture resulted

340 in a positive Pearson correlation in 2018 for all sample types (average $\mathrm{P}=0.01, \mathrm{R}^{2}=0.95$ );

341 however, no significant correlation was determined for the year 2017. In August 2017, peaks in

$342 \mathrm{CO}_{2}$ production for the lodgepole $\left(5,600 \pm 1,100 \mathrm{mg}_{-} \mathrm{C} \mathrm{m}^{-2} \mathrm{~d}^{-1}\right)$ and healthy spruce needles

$343\left(5,400 \pm 500 \mathrm{mg}_{-} \mathrm{C} \mathrm{m}^{-2} \mathrm{~d}^{-1}\right)$ were almost two-fold higher than the needle-free control $2017(3,200$

$\left.344 \pm 500 \mathrm{mg}_{-} \mathrm{C} \mathrm{m}^{-2} \mathrm{~d}^{-1}\right)$. This peak in production was followed by a return to baseline conditions by

345 the next sampling event (Fig. 3A). An analogous $\mathrm{CO}_{2}$ peak was observed in 2018 after a

346 moisture event in late June despite overall drier annual soil conditions. Interestingly, during the

347 two high moisture time points, the decomposition of healthy spruce needles released more $\mathrm{CO}_{2}$ 
348 than impacted spruce in $2017\left(5,400 \pm 500 \mathrm{mg}-\mathrm{C} \mathrm{m} \mathrm{m}^{-2} \mathrm{~d}^{-1}\right.$ versus $4,100 \pm 500 \mathrm{mg}-\mathrm{C} \mathrm{m}^{-2} \mathrm{~d}^{-1}$

349 respectively); however, this trend was muted and potentially reversed in $2018(2,200 \pm 400 \mathrm{mg}-\mathrm{C}$

$350 \mathrm{~m}^{-2} \mathrm{~d}^{-1}$ versus $2800 \pm 200 \mathrm{mg}-\mathrm{C} \mathrm{m}^{-2} \mathrm{~d}^{-1}$, respectively). Sampling throughout 2017 and 2018

351 provided interesting insights related to seasonal parameters due to contrasting seasonal

352 temperature and moisture conditions between years. The hourly soil conditions collected during

353 each gas flux measurement averaged $14{ }^{\circ} \mathrm{C}, 16 \%$ moisture in 2017 and $21{ }^{\circ} \mathrm{C}, 10 \%$ moisture in

3542018 (Fig. 3C,D). These observed differences in soil temperature and moisture coincide with

355 lower $\mathrm{CO}_{2}$ peaks for all sample types during the drier 2018 monsoon season.

356 Methane flux averaged a removal rate of $-1 \mathrm{mg} \mathrm{C} \mathrm{m}^{-2} \mathrm{day}^{-1}$ above needle and control

357 samples with no clear differences in association with needle presence in contrast to the control.

358 Seasonal trends in $\mathrm{CH}_{4}$ behaved similarly to the observed $\mathrm{CO}_{2}$ fluxes in which the data points

359 appear to correspond with soil moisture (Fig. S2). Nitrous flux was near ambient conditions with

360 no clear trends apparent as a function of uptake or release. Ammonia was also monitored;

361 however, no clear trends were apparent as a function of uptake or release among field triplicates.

3623.3 Soil and porewater signatures

363 The 2017 and 2018 porewater collections revealed over time that the healthy spruce and

364 lodgepole needles exported higher DOC concentrations within the aqueous near-surface in

365 contrast to the control and impacted spruce samples. No clear trends were determined in total

366 nitrogen concentrations during June 2017 due to high variability in lodgepole $(0.38 \pm 0.14$

$367 \mathrm{mg} / \mathrm{L})$, healthy spruce $(0.67 \pm 0.29 \mathrm{mg} / \mathrm{L})$ and impacted spruce $(0.49 \pm 0.19 \mathrm{mg} / \mathrm{L})$. May 2018

368 sampling returned values below detection for all samples except for lodgepole $(0.32 \pm 0.30$

$369 \mathrm{mg} / \mathrm{L}$ ). Late season measurements in October 2017 revealed similar concentrations between

370 healthy spruce $(0.79 \pm 0.29 \mathrm{mg} / \mathrm{L})$ and lodgepole $(0.63 \pm 0.24 \mathrm{mg} / \mathrm{L})$ and lower concentrations for 
371 impacted spruce needles $(0.38 \pm 0.12 \mathrm{mg} / \mathrm{L})$. Late season 2018 sampling returned similar

372 concentrations between healthy spruce $(0.92 \pm 0.29 \mathrm{mg} / \mathrm{L})$ and lodgepole $(0.76 \pm 0.10 \mathrm{mg} / \mathrm{L})$ and

373 lower concentrations released by impacted spruce needles $(0.57 \mathrm{mg} / \mathrm{L})$ however no standard

374 deviation could be calculated due to low porewater yields. There were no clear differences in

375 aromatic signatures (SUVA) as a function of needle presence (Table 2).

376 Soil extractions in October 2017 agree with the porewater results of higher soil DOC

377 concentrations in association with needle decomposition. Interestingly, in contrast to the

378 harvested needle water extraction analysis, soil porewater under lodgepole needles contained the

379 highest extractable DOC compared to the spruce needles, reaching more than a two-fold higher

380 concentration (Table 3). Overall, the total extractable nitrogen in soil under all needle samples

381 were lower than the control; however, differences in nitrogen speciation as a function of needle

382 presence are apparent. The inorganic nitrogen species are low in association with needle

383 decomposition while organic nitrogen comprised the highest percentage of the total nitrogen in

384 soil associated with needle decomposition in contrast to the control. Specifically, organic

385 nitrogen comprised an average of $86 \%$ of the total nitrogen in all three soil types associated with

386 needle decomposition, while a lower percentage (50\%) was observed in the needle-free control

387 (Table 3). In addition, the needles resulted in lower soil $\mathrm{pH}$ values (average of $6.1 \pm 0.2$ across

388 needle samples) than that of the control $(\mathrm{pH} \sim 6.6)$.

389 3.4 Soil microbial communities in association with needle decomposition

390 Beta diversity differed as a function of sample type for both fungal and bacterial soil

391 communities. Similar to gas flux, the most significant clustering determined by principal

392 coordinate analysis was observed during or after high moisture events sampled in August 2017

393 and July 2018 (weighted UniFrac Adonis test: bacterial: $\mathrm{p}<0.05$ and fungal: $\mathrm{p}<0.01$; Fig. 4). 
394 Consistent with the geochemical analyses, soil communities associated with needle samples

395 clustered separately from controls. To a lesser extent, communities under lodgepole

396 decomposition were distinct from those under spruce needles. In contrast, communities under the

397 impacted spruce needles were indistinguishable from healthy spruce. Despite significant

398 community clustering, alpha diversity metrics were not significantly impacted by the

399 decomposition of different needle types in comparison to the control (Fig. S3).

400 To further investigate differences in microbial communities in soil under the needle

401 samples, differential abundance tests were conducted on the top 15 most abundant genera during

402 the 2017 and 2018 high moisture sampling events to determine differentiation in relative

403 abundances at the genus level (Fig. 5). There were no significant differences between the shaded

404 and exposed needle-free control samples or for healthy and impacted spruce. Communities under

405 the lodgepole needles were most different from those found under the control with increasing

406 significance in 2018 (Fig. 5; S4). Specifically, lodgepole significantly differed from the control

407 in higher abundances of potential nitrogen fixers of the genera Bradyrhizobium and Variibacter.

408 In addition, by comparing lodgepole and the controls, lower abundances of chemoorganotrophs

409 Segetibacter, Flavisolibacter, Ferruginibacter and a potential nitrogen fixer Massilia were

410 observed in the lodgepole samples. Further, comparing lodgepole to the binned spruce samples,

411 lodgepole is significantly lower in abundance of Ferruginibacter, Segetibacter and Massilia.

412 Binned impacted and healthy spruce samples significantly differed from the controls with higher

413 abundance of Chthoniobacter and lower abundances of Segetibacter and Flavisolibacter (Fig. 5).

414 Turning to Eukarya, larger variations in relative abundance were observed and taxonomic

415 rank was not completed at the Genus or Family level. Few significant differences were

416 determined with differential abundance tests; however, basic comparisons between samples were 
417 possible. Fungal communities followed a similar trend to bacteria in which the communities

418 under impacted and healthy spruce needles are similar, while there are differences between

419 lodgepole and spruce (Fig. S5.) Further, based on mean relative abundances the Phylum

420 Ascomycota comprised 50\% mean abundance under the control, $52 \%$ under healthy spruce, $40 \%$

421 under impacted spruce, and 25\% under lodgepole samples (Fig. S6). In contrast Basidiomycota

422 represented $36 \%$ of the mean abundance under lodgepole and $10-19 \%$ under the spruce and 423 control samples (Fig. S6).

\section{4. Discussion}

425 We gained a better understanding of the effects of needle decomposition on terrestrial soil

426 biogeochemical processes by studying the compositional differences of senesced coniferous

427 needles between two species and as a function of bark beetle impact. Additionally, by isolating

428 the needle litter from the complexity of the tree canopy and rhizosphere, we were able to

429 investigate the selective pressures derived from litter presence and decomposition over time

430 under the same environmental conditions. By extension, this enhanced our understanding of

431 biogeochemical cycling in natural and disrupted ecosystems. However, it is noted that

432 conclusions with respect to bark beetle impacts are limited in our dataset to spruce trees and the

433 study was further limited to two conifer species. Three key findings emerged from this study: 1)

434 Under the same conditions and location, tree species exerts a larger role in needle decomposition

435 dynamics than bark beetle impact, 2) conifer litter decomposition enhances soil organic carbon

436 and nitrogen cycling, heterotrophic respiration, and exerts pressures on resident microbial

437 ecology, and 3) biogeochemical signatures are enhanced during high moisture conditions.

438 4.1 Needle litter chemistry 
The behavior of plant litter as it decomposes can be attributed to the quality of organic

440 matter available for microbial decomposition. The amount of bioavailable nutrients and organic

441 matter within the needles depends on the plant phenology, which determines the physiology of

442 carbon and nitrogen storage throughout the tree (Millard \& Grelet, 2010). Differences in initial

443 litter quality can affect soil chemistry and microbial communities with the potential for more

444 microbial activity associated with higher quality litter, which can in turn affect soil $\mathrm{C}$ and $\mathrm{N}$

445 retention within the first year of decomposition (Šantrůčková, Krištůfková, and Vaněk, 2006;

446 Fraterrigo, Ream, and Knoepp, 2018). As a result, discrete differences in organic content and

447 nutrients as a function of needle type can shed light on the expected behavior of plant litter

448 decomposition in the environment. To this end, high quality litter is understood to have higher

449 nitrogen concentrations (low C:N ratios) and low recalcitrance, which can be estimated by lignin

450 content. Following this understanding, the results of total C, N and FTIR analysis revealed that

451 the harvested naturally senesced lodgepole needles are a higher quality substrate than naturally

452 senesced spruce, while the beetle impacted spruce needles are of the lowest quality. A similar

453 study comparing senesced conifer litter decomposition rates across forests within the Rocky

454 Mountains agree with the conclusion that lodgepole contains the lowest lignin levels, but

455 contrasts with our observation of lodgepole containing the highest $\mathrm{C}: \mathrm{N}$ ratio (Stump and Binkley,

456 1993). After two years of decomposition, the same results by Stump and Binkley in 1993 agree

457 with the trend described in this study of a decrease in $\mathrm{C}: \mathrm{N}$ for the spruce needles and an increase

458 in lodgepole. The total carbon losses in this study after two years of decomposition revealed a

459 modest decrease in lodgepole compared to the impacted spruce needles and a large standard

460 deviation in the healthy spruce (Table S1). While a lack of mass balance quantification limits

461 interpretation, possible explanations include decomposer biomass formation as well as different 
462 mass loss rates associated with hydrolysis and oxidation due to the physical differences in needle

463 shape and size between tree species (Ono et al., 2011).

464 FTIR analysis revealed lower quantities of lignin and higher quantities of cellulose in the

465 lodgepole needles compared to both spruce needle types throughout two years of decomposition

466 (Fig. 2). These observations indicate functional differences in the decomposition processes of

467 lodgepole and spruce needles. This observation agrees with a litter decomposition study by He et

468 al. in 2019 that reported periodic lignin losses associated with increases in cellulose. Lignin and

469 cellulose decomposition processes can be controlled by climate, litter quality, and the

470 decomposers present (He et al., 2019). With the variability of climate and native soil

471 microorganisms removed in this study, the needle chemistry is likely the main driver of the

472 differences observed in decomposition across needle type. Lignin and cellulose decomposition

473 appear to be linked, which can be attributed to the organization of polymers within plant cell

474 walls. A greater distribution of lignin can prevent decomposers from accessing more labile

475 organics within the cell (Berg \& McClaugherty, 2014). As a result, litter types with higher levels

476 of lignin may exhibit reduced decomposition rates until lignin degradation occurs. This explains

477 why the lodgepole needles behave differently from the spruce needles which contain higher

478 lignin levels.

4794.2 Carbon \& nitrogen cycling

480 During the process of decomposition, soil carbon and nitrogen speciation can shift as a

481 result of abiotic and biotic factors. Specifically, chemical attributes of soils can influence

482 decomposition processes differently across tree species (Vesterdal, 1999; Berg, 2000). By

483 importing conifer needles to the same location, this study limited these effects to focus on the

484 variable of needle litter chemistry. With this in mind, studies have reported similar observations 
485 across a variety of study locations which include increased inorganic soil nitrogen in association

486 with bark beetle impact (Clow et al., 2011; Brouillard et al., 2017). Interestingly, while the

487 harvested impacted spruce needle extractions returned the highest total nitrogen concentrations,

488 inconsistent and contrasting trends in porewater total nitrogen and organic carbon were observed.

489 Differences between the initial needle extractions and porewater composition over two years can

490 be influenced by changes in nutrient distribution and quantity within the needles when

491 decomposition begins (Berg \& McClaugherty, 2014).

492 A study by Kopáček et al. in 2018 observed terrestrial nitrogen speciation significantly

493 responded to Norway spruce bark beetle tree death with increased $\mathrm{NH}_{4}{ }^{+}$in the soil adjacent to

494 tree dieback due to mineralization of organic $\mathrm{N}$ in the decomposing plant matter followed by

495 nitrification. In contrast, this study revealed lower concentrations of inorganic nitrogen in soil

496 under all needle samples when compared to the needle-free control. As a result, the fraction of

497 organic nitrogen comprising the total extractable nitrogen in soil after one year of decomposition

498 was the highest under all needle samples (Table 3). This observation of high organic nitrogen

499 and relatively low inorganic nitrogen could be due to the dependency of nitrogen distribution on

500 the litter C:N ratio. According to a study by Šantrůčková, Krištůfková \& Vaněk in 2006, a litter

$501 \mathrm{C}: \mathrm{N}$ threshold value of 32 is the point in which mineralized soil nitrogen concentrations begin to

502 release in measurable concentrations. This threshold ratio value varies between studies, as it is

503 dependent on the site location, litter age, and species (Eldhuset, Kjønaas \& Lange, 2017). The

504 C: $N$ ratios in the needles specific to this study were above 45 during two years of decomposition.

505 In addition, due to the dominance of organic nitrogen in soils associated with needle

506 decomposition in contrast to the control, the needle chemistry appears to enhance microbial $\mathrm{N}$

507 accumulation while little $\mathrm{N}$ mineralization is occurring. This agrees with other results in which 
508 nitrogen mineralization was low for lodgepole and moderate for spruce during decomposition

509 (Stump \& Binkley, 1993).

510 In addition to nitrogen shifts in association with needle decomposition, the study by

511 Kopáček et al., 2018 revealed increased soil DOC concentrations within the first years of beetle

512 impacted Norway spruce tree death due to organic carbon production from dead biomass. Our

513 results exhibit similar results of increased near-surface carbon cycling in association with

514 seasonal $\mathrm{CO}_{2}$ production and higher magnitudes of extractable DOC in soil underlying needle

515 decomposition. The largest magnitude of $\mathrm{CO}_{2}$ production was observed in association with

516 lodgepole needles, especially during high moisture events in which respiration was almost two-

517 fold higher than the needle-free controls. Heightened decomposition of higher quality litter leads

518 to nutrient utilization and ultimately terrestrial microbial respiration, which in turn is expected to

519 decompose more quickly initially (Berg, 2000; Fraterrigo, Ream \& Knoepp, 2018). As a result,

520 lodgepole forests may contribute a larger flux of $\mathrm{CO}_{2}$ to the atmosphere during needle drop

521 compared to spruce forests, especially during warmer snow-free seasons with higher soil

522 moisture. Looking closer at healthy versus impacted spruce needles, clear differences were not

523 determined in $\mathrm{CO}_{2}$ flux magnitudes between these needle types despite chemical differences,

524 which suggests that beetle impacted spruce needle drop alone will not shift forest soil respiration

525 rates from that of naturally senesced spruce needles. Past studies comparing impacted forest plots

526 to non-impacted have shown variations in results, but with a consensus of respiration values that

527 are lower or unchanged in soil under impacted trees in comparison to soils under healthy trees

528 for both spruce (Speckman et al., 2015) and lodgepole (Brouillard et al., 2017).

529 4.3 Soil microbial selection 
531 insights into the collective impacts of needle decomposition. Past studies have documented shifts

532 in soil bacterial (Mikkelson, Lozupone \& Sharp, 2016; Mikkelson et al., 2017) and fungal

533 communities (Štursová et al., 2014) after beetle infestation. However, these observed shifts are

534 related to variables that include litter decomposition and the cessation of rhizodeposition among

535 other variables such the changing water and energy budgets that occur during tree mortality

536 (Mikkelson et al., 2011). As significance was most pronounced near high moisture events, our

537 results suggest that litter decomposition plays a more significant role in microbial community

538 selection during the summer wet season when top down infiltration is occurring.

539 In comparing the bacterial communities, the presence of higher quality litter also exerted

540 the strongest selective pressures on microbial communities. Interestingly, despite initial chemical

541 differences between naturally senesced and beetle impacted spruce needles, no significant

542 differences in microbial differential abundance were observed. This suggests that inherent

543 complex organics associated with the tree species exert a stronger impact on biogeochemical

544 cycling, while the impact of beetle infestation on the tree has little to no impact on the

545 decomposition processes of spruce litter. This agrees with litter quality decomposition studies

546 that have concluded complex organics, as well as other elements are the driving force of litter

547 decomposition over C:N ratios (Fogel \& Cromack Jr., 1977; Hobbie, 2015).

548 The increased relative abundance of putative nitrogen fixers (Bradyrhizobium and

549 Varibacter) associated with rhizospheric processes suggests that the conditions necessary for

550 nitrogen fixation are present within the needle decomposition horizon. However, due to the lack

551 of observed mineralization in the soil chemistry, and no predominant abundance of

552 ammonification, nitrifying, or denitrifying bacteria, the results reveal how crucial the rhizosphere 
553 is for the complete cycling of nitrogen and further why larger impacts to the nitrogen cycle are

554 not observed in this study. This suggests that while the needle litter decomposition contributed

555 to carbon cycling in this study, nitrogen cycling and especially inorganic nitrogen is likely linked

556 to other mechanisms at the tree-scale, such as belowground nutrient contributions associated

557 with rhizodeposits.

558 5. Conclusion

559 The results of this study shed light on the complex behavior of needle decomposition as a

560 function of abiotic and biotic factors that are associated with temporal decomposition. Over a

561 study period of two years, we have gained further insight into the expected impacts during the

562 first stages of litterfall for healthy and beetle disrupted ecosystems. In a situation where needles

563 fall to the forest floor following tree mortality it is likely that observable impacts will consist of

564 increased $\mathrm{CO}_{2}$ production from heterotrophic activity while enhanced inorganic nitrogen cycling

565 will occur depending on the $\mathrm{C}: \mathrm{N}$ ratio of the litter and rhizospheric processes. As more

566 noticeable impacts on soil flux and microbial communities were observed during high moisture

567 events, the biogeochemical signatures will be most pronounced in high moisture environments.

568 This has been observed in past studies, in which moisture is correlated with higher coniferous

569 decomposition rates (Pandey \& Singh, 1982; Gunadi, Verhoef \& Bedaux, 1998).

570 The expected outcomes of litter decomposition on soil biogeochemistry will differ as a

571 function of tree species. It can be expected that lodgepole forest soil microbial communities will

572 be different from those of a spruce forest within the first two years of decomposition after needle

573 fall. During bark beetle infestation, needle decomposition is likely to exert a comparatively

574 modest selective pressure on soil biogeochemistry when contrasted with other forest relevant 
575 processes such as evapotranspiration, canopy interception, energy fluxes, as well as

576 rhizodeposition and the cessation of such processes.

577

578 Acknowledgements

579 Field access and support were provided by the Rocky Mountain Biological Laboratory in Gothic,

580 CO with logistical support from Jennifer Reithel. We thank Chelsea Wilmer, Kayla Hubbard,

581 Jake Wands, and Sabrina Nesladek for field support. Alexander Honeyman, Blake Stamps, and

582 Gary Vanzin aided in laboratory and bioinformatic techniques, as well as all members in the

583 Geo-Environmental Microbiology Lab at the Colorado School of Mines. We thank PeerJ editor

584 Douglas Burns, Jenna Zukswert, and an anonymous reviewer for their insightful suggestions

585 during the peer review processes.

586

587 References

5882015 Report on the Health of Colorado's Forests: 15 Years of Change. 2016. Colorado State

589 Forest Service, Colorado Department of Natural Resources, Colorado State University.

5902017 Report on the health of Colorado's forests. 2018. Colorado State Forest Service, Colorado

591 Department of Natural Resources, Colorado State University.

592 Andersen KS, Kirkegaard RH, Karst SM, Albertsen M. 2018. ampvis2: an R package to analyse 593 and visualise 16S rRNA amplicon data. bioRxiv:299537. DOI: 10.1101/299537.

594 Bark Beetles - US Forest Service Research \& Development Bark Beetles. 2019. Available at 595 https://www.fs.fed.us/research/invasive-species/insects/bark-beetle/(accessed October 9, $5962019)$. 
597 Bearup LA, Maxwell RM, Clow DW, McCray JE. 2014. Hydrological effects of forest

598 transpiration loss in bark beetle-impacted watersheds. Nature Climate Change 4:481599 486. DOI: $10.1038 /$ nclimate2198.

600 Berg B. 2000. Litter decomposition and organic matter turnover in northern forest soils. Forest 601 Ecology and Management 133:13-22. DOI: 10.1016/S0378-1127(99)00294-7.

602 Berg B, McClaugherty C. 2014. Plant Litter: Decomposition, Humus Formation, Carbon 603 Sequestration. Berlin Heidelberg: Springer-Verlag. DOI: 10.1007/978-3-642-38821-7.

604 Brouillard B, Mikkelson K, Bokman C, Berryman EM, Sharp J. 2017. Extent of localized tree 605 mortality influences soil biogeochemical response in a beetle-infested coniferous forest. 606 Soil Biology and Biochemistry 114:309318. DOI: 10.1016/j.soilbio.2017.06.016.

607 Callahan BJ, McMurdie PJ, Rosen MJ, Han AW, Johnson AJA, Holmes SP. 2016. DADA2: High-resolution sample inference from Illumina amplicon data. Nature Methods 13:581583. DOI: $10.1038 /$ nmeth.3869.

610 Caporaso JG, Lauber CL, Walters WA, Berg-Lyons D, Huntley J, Fierer N, Owens SM, Betley J, Fraser L, Bauer M, Gormley N, Gilbert JA, Smith G, Knight R. 2012. Ultra-highthroughput microbial community analysis on the Illumina HiSeq and MiSeq platforms.

614 Cigan PW, Karst J, Cahill JF, Sywenky AN, Pec GJ, Erbilgin N. 2015. Influence of bark beetle 615 outbreaks on nutrient cycling in native pine stands in western Canada. Plant and Soil 390:29-47. DOI: 10.1007/s11104-014-2378-0.

617 Clow DW, Rhoades CC, Briggs J, Caldwell M, Lewis WM. 2011. Responses of soil and water 618 chemistry to mountain pine beetle induced tree mortality in Grand County, Colorado, 
621 Edburg SL, Hicke JA, Brooks PD, Pendall EG, Ewers BE, Norton U, Gochis D, Gutmann ED, Meddens AJ. 2012. Cascading impacts of bark beetle-caused tree mortality on coupled biogeophysical and biogeochemical processes. Frontiers in Ecology and the Environment 10:416-424. DOI: 10.1890/110173.

625

Eldhuset TD, Kjønaas OJ, Lange H. 2017. Decomposition rates and nutrient dynamics of Picea abies needles, twigs and fine roots after stem-only harvesting in eastern and western Norway. Plant and Soil 418:1-19. DOI: 10.1007/s11104-017-3302-1.

Fogel R, Cromack Jr. K. 1977. Effect of habitat and substrate quality on Douglas fir litter decomposition in western Oregon. Canadian Journal of Botany 55:1632-1640. DOI: 10.1139/b77-190.

Fraterrigo JM, Ream K, Knoepp JD. 2018. Tree Mortality From Insect Infestation Enhances Carbon Stabilization in Southern Appalachian Forest Soils. Journal of Geophysical Research: Biogeosciences 123:2121-2134. DOI: 10.1029/2018JG004431.

Gunadi B, Verhoef HA, Bedaux JJM. 1998. Seasonal dynamics of decomposition of coniferous leaf litter in a forest plantation (Pinus merkusii) in Central Java, Indonesia. Soil Biology and Biochemistry 30:845-852. DOI: 10.1016/S0038-0717(98)00014-5.

He W, Shujiao M, Pei, Teng, Zeng X, Yan Y, Huang, Wang K, Yun L, Xiao W. 2019. Effects of Predominant Tree Species Mixing on Lignin and Cellulose Degradation during Leaf Litter Decomposition in the Three Gorges Reservoir, China. Forests 10:360. DOI: $10.3390 / \mathrm{f} 10040360$. 
641 Hicks Pries CE, Bird JA, Castanha C, Hatton P-J, Torn MS. 2017. Long term decomposition: the 642 influence of litter type and soil horizon on retention of plant carbon and nitrogen in soils. 643 Biogeochemistry 134:5-16. DOI: 10.1007/s10533-017-0345-6.

644 Hlásny T, Krokene P, Liebhold A, Montagné-Huck C, Müller J, Qin H, Raffa K, Schelhaas M-J, 645 Seidl R, Svoboda M, Viiri H. 2019. Living with bark beetles: impacts, outlook and management options. :52.

Hobbie SE. 2015. Plant species effects on nutrient cycling: revisiting litter feedbacks. Trends in 648 Ecology \& Evolution 30:357-363. DOI: 10.1016/j.tree.2015.03.015.

649

650

651

652

653

654

655

656

657

658

659

660

661

662

663
Honeyman AS, Day ML, Spear JR. 2018. Regional fresh snowfall microbiology and chemistry are driven by geography in storm-tracked events, Colorado, USA. PeerJ 6:e5961. DOI: $10.7717 /$ peerj.5961.

Kopáček J, Evans CD, Hejzlar J, Kaňa J, Porcal P, Šantrůčková H. 2018. Factors Affecting the Leaching of Dissolved Organic Carbon after Tree Dieback in an Unmanaged European Mountain Forest. Environmental Science \& Technology 52:6291-6299. DOI: 10.1021/acs.est.8b00478.

Love MI, Huber W, Anders S. 2014. Moderated estimation of fold change and dispersion for RNA-seq data with DESeq2. Genome Biology 15:550. DOI: 10.1186/s13059-014-0550-8.

McMurdie PJ, Holmes S. 2013. phyloseq: An R Package for Reproducible Interactive Analysis and Graphics of Microbiome Census Data. PLOS ONE 8:e61217. DOI: 10.1371/journal.pone.0061217.

Mikkelson K, Bearup L, Maxwell R, Stednick J, McCray J, Sharp J. 2013. Bark beetle infestation impacts on nutrient cycling, water quality and interdependent hydrological effects. Biogeochemistry 115:1-21. DOI: 10.1007/s10533-013-9875-8.

Peer) reviewing PDF | (2020:02:45793:1:1:NEW 3 Jun 2020) 
664 Mikkelson KM, Brouillard BM, Bokman CM, Sharp JO. 2017. Ecosystem Resilience and

665 Limitations Revealed by Soil Bacterial Community Dynamics in a Bark Beetle-Impacted 666 Forest. mBio 8:e01305-17. DOI: 10.1128/mBio.01305-17.

667 Mikkelson K, Lozupone CA, Sharp JO. 2016. Altered edaphic parameters couple to shifts in 668 terrestrial bacterial community structure associated with insect-induced tree mortality. Soil Biology and Biochemistry C:19-29. DOI: 10.1016/j.soilbio.2015.12.001.

Mikkelson KM, Maxwell RM, Ferguson I, Stednick JD, McCray JE, Sharp JO. 2011. Mountain pine beetle infestation impacts: modeling water and energy budgets at the hill-slope scale. Ecohydrology 6:64-72. DOI: 10.1002/eco.278.

Millard P, Grelet G-A. 2010. Nitrogen storage and remobilization by trees: ecophysiological relevance in a changing world. Tree Physiology 30:1083-1095. DOI: 10.1093/treephys/tpq042.

Mountain pine beetle | Natural Resources Canada. 2013. Available at https://www.nrcan.gc.ca/our-natural-resources/forests-and-forestry/wildland-firesinsects-and-disturbances/top-forest-insects-and-diseases-canada/mountain-pinebeetle/13381 (accessed July 17, 2019).

Negrón JF, Cain B. 2018. Mountain Pine Beetle in Colorado: A Story of Changing Forests. Journal of Forestry. DOI: 10.1093/jofore/fvy032.

682 Oksanen J, Blanchet FG, Friendly M, Kindt R, Legendre P, McGlinn D, Minchin PR, O’Hara 683 RB, Simpson GL, Solymos P, Stevens MHH, Szoecs E, Wagner H. 2019. vegan: Community Ecology Package. forest floors in Japanese cedar (Cryptomeria japonica) and Hinoki cypress 
(Chamaecyparis obtusa) plantations in Japan. Plant and Soil 338:171-181. DOI:

Özgenç Ö, Durmaz S, Kuştaş S. 2017. Chemical Analysis of Tree Barks using ATR-FTIR Spectroscopy and Conventional Techniques. BioResources 12:9143-9151.

691 Pandey KK, Pitman AJ. 2003. FTIR studies of the changes in wood chemistry following decay 692 by brown-rot and white-rot fungi. International Biodeterioration \& Biodegradation 52:151-160. DOI: 10.1016/S0964-8305(03)00052-0.

Pandey U, Singh JS. 1982. Leaf-Litter Decomposition in an Oak-Conifer Forest in Himalaya: The Effects of Climate and Chemical Composition. Forestry: An International Journal of

Potter BB, Wimsatt JC. 2009. Determination of total organic carbon and specific UV

absorbaance at $254 \mathrm{~nm}$ in source water and drinking water. Office of Research and Forest Research 55:47-59. DOI: 10.1093/forestry/55.1.47.

Parada AE, Needham DM, Fuhrman JA. 2016. Every base matters: assessing small subunit rRNA primers for marine microbiomes with mock communities, time series and global field samples. Environmental Microbiology 18:1403-1414. DOI: 10.1111/1462-

2920.13023.

Development: U.S. EPA National Exposure Research Laboratory.

Pruesse E, Peplies J, Glöckner FO. 2012. SINA: Accurate high-throughput multiple sequence alignment of ribosomal RNA genes. Bioinformatics 28:1823-1829. DOI:

706 10.1093/bioinformatics/bts252. plant litter of Norway spruce forest in the Bohemian Forest. Biologia 61:S499-S508. DOI: $10.2478 / \mathrm{s} 11756-007-0073-9$. 
710 Soil Survey Staff, Natural Resources Conservation Service, United States Department of

711 Agriculture. Web Soil Survey. Available at http://websoilsurvey.nrcs.usda.gov/(accessed

$712 \quad$ May 14, 2020).

713 Speckman HN, Frank JM, Bradford JB, Miles BL, Massman WJ, Parton WJ, Ryan MG. 2015.

714 Forest ecosystem respiration estimated from eddy covariance and chamber measurements

715 under high turbulence and substantial tree mortality from bark beetles. Global Change

716 Biology 21:708-721. DOI: 10.1111/gcb.12731.

717 Stamps BW, Lyles CN, Suflita JM, Masoner JR, Cozzarelli IM, Kolpin DW, Stevenson BS.

718 2016. Municipal Solid Waste Landfills Harbor Distinct Microbiomes. Frontiers in

719 Microbiology 7. DOI: 10.3389/fmicb.2016.00534.

720 Stump LM, Binkley D. 1993. Relationships between litter quality and nitrogen availability in

721 Rocky Mountain forests. Canadian Journal of Forest Research 23:492-502. DOI:

722 10.1139/x93-067.

723 Štursová M, Šnajdr J, Cajthaml T, Bárta J, Šantrůčková H, Baldrian P. 2014. When the forest 724 dies: the response of forest soil fungi to a bark beetle-induced tree dieback. The ISME 725 Journal 8:1920-1931. DOI: 10.1038/ismej.2014.37.

726 U.S. Geological Survey, 2005, Mineral Resources Data System: U.S. Geological Survey, 727 Reston, Virginia. Available at https://mrdata.usgs.gov/mrds/ (accessed May 14, 2020). 728 Vesterdal L. 1999. Influence of soil type on mass loss and nutrient release from decomposing 729 730 foliage litter of beech and Norway spruce. Canadian Journal of Forest Research 29:95105. DOI: $10.1139 / \times 98-182$. 


\section{Figure 1}

Differences in needle carbon, nitrogen, and organics composition.

(A) Percentages of carbon and nitrogen needle composition represented as the carbon:nitrogen ratio $(n=3)$ for the harvested needles (2016) and after two years of decomposition (2018). Error bars represent plus or minus one standard deviation and points on the plot represent actual values. (B) FTIR spectra for the initial needles and (C) after two years of decomposition. Peak heights at specific wavenumbers reveal differences in the spectra as a function of needle species. Total carbon and nitrogen percentages can be found in Table S1. 

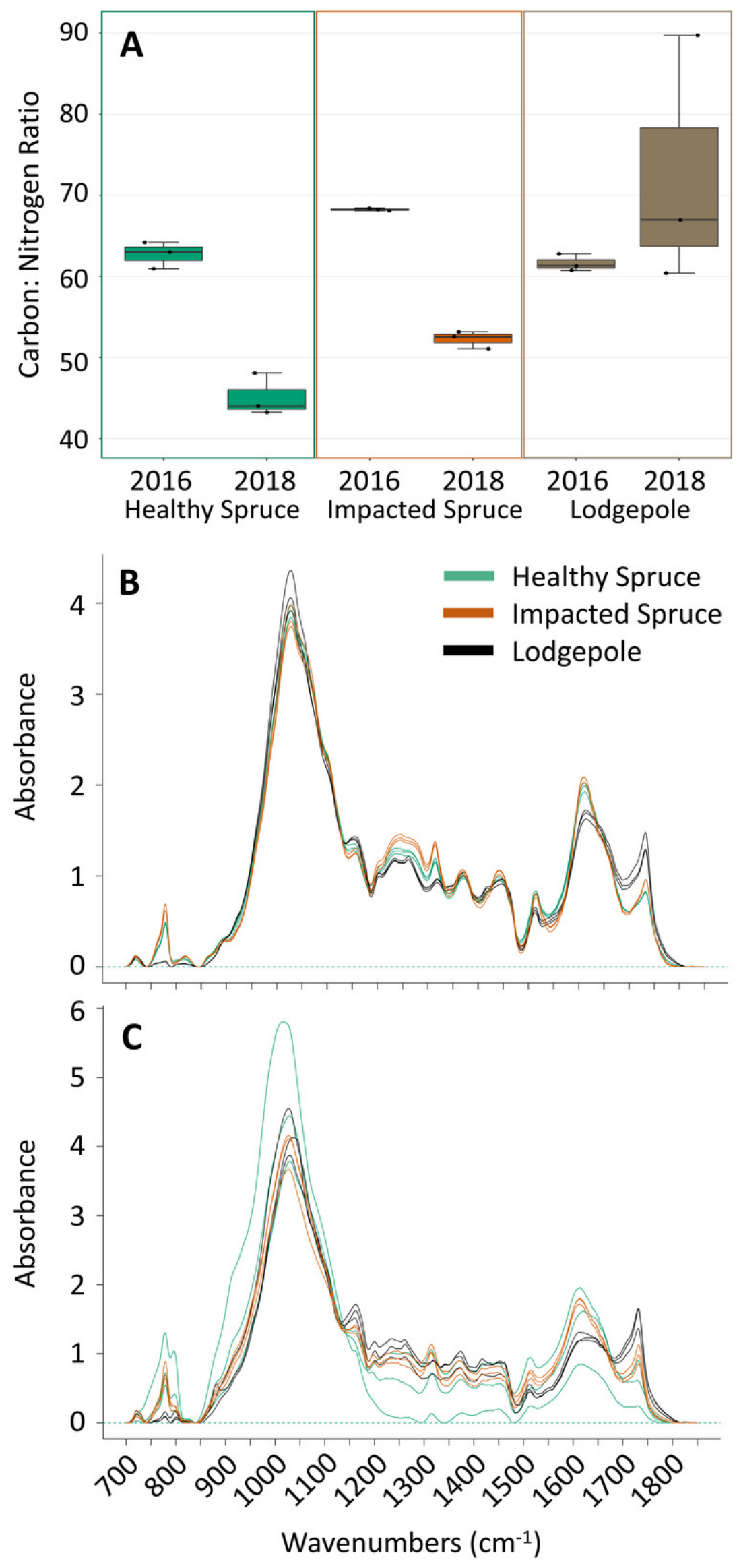

PeerJ reviewing PDF | (2020:02:45793:1:1:NEW 3 Jun 2020) 


\section{Figure 2}

Differences in integrated FTIR spectra peak areas.

Integrated areas of peak absorbance at wavenumbers with clear differences for the initial needles (2016) and after two years of decomposition (2018). Peak areas suggest differences in the chemical composition between needles, notably (A) ether linkages $\left(1150 \mathrm{~cm}^{-1}\right)$, (B) aromatics $\left(1510 \mathrm{~cm}^{-1}\right),(C)$ amides $\left(1600 \mathrm{~cm}^{-1}\right)$, and (D) carbonyl signatures $\left(1720 \mathrm{~cm}^{-1}\right)$. (E) The ratio of ether linkages to aromatics is also shown. Tabulated values of each area can be found in Table S2. 
A
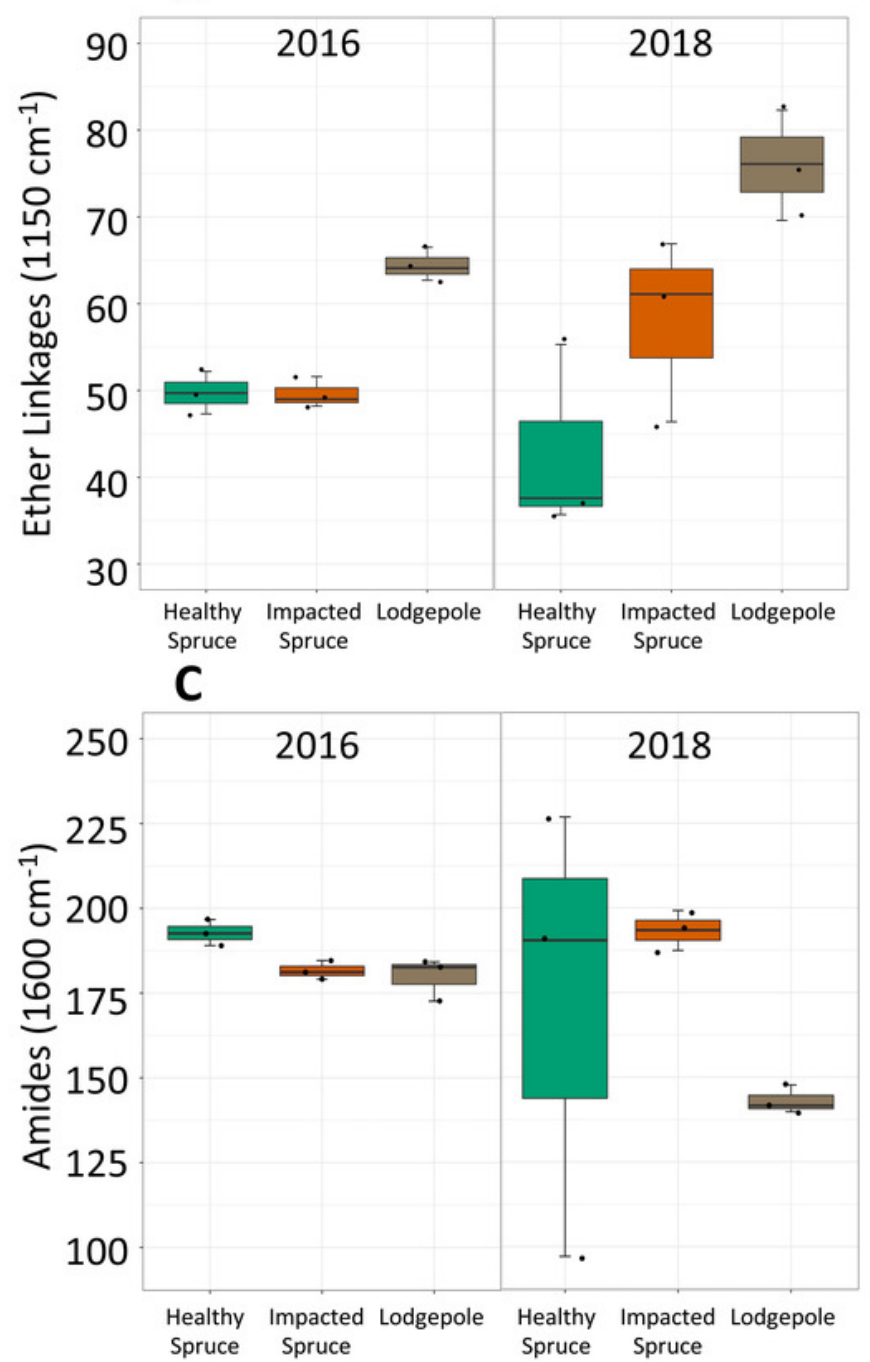

E

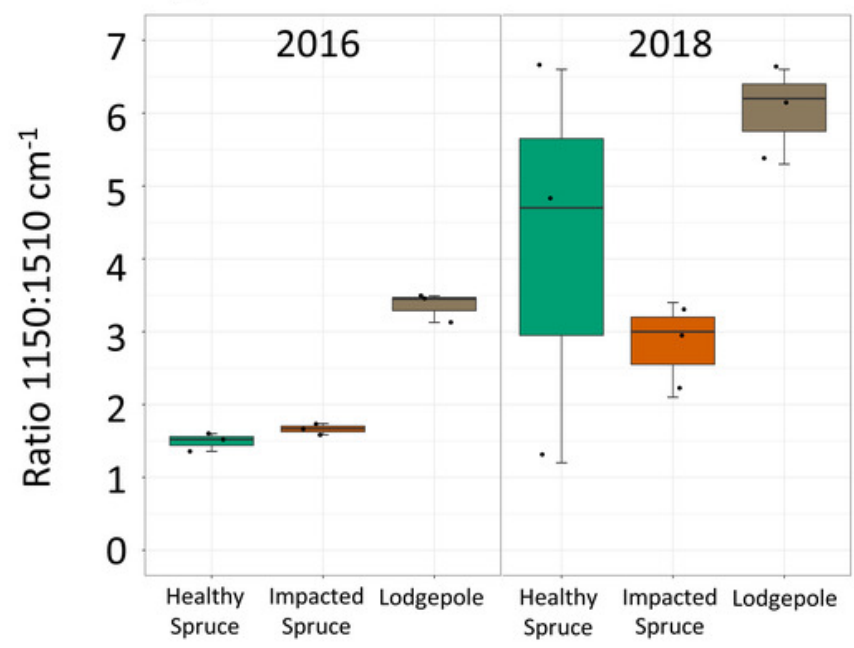

B

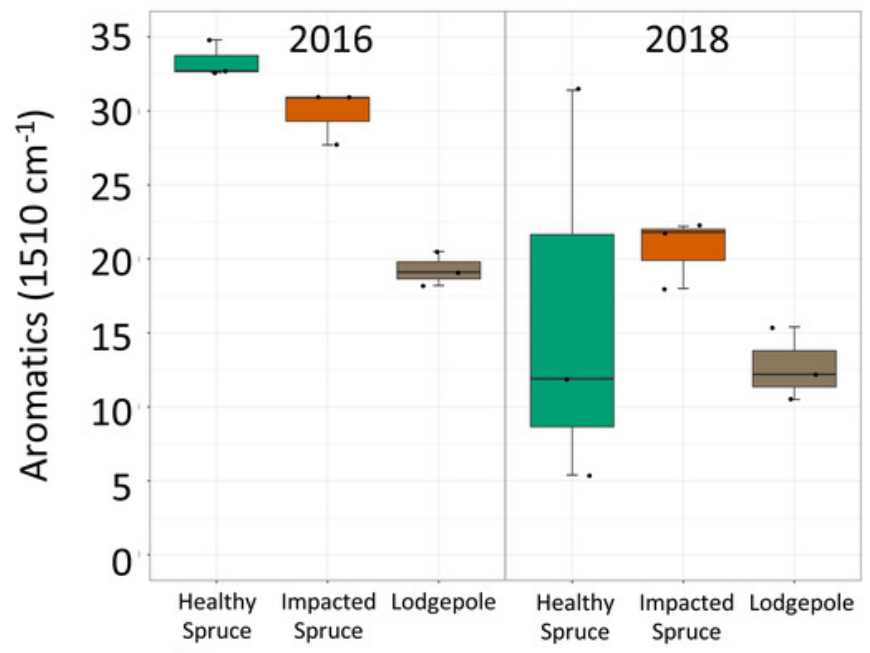

D

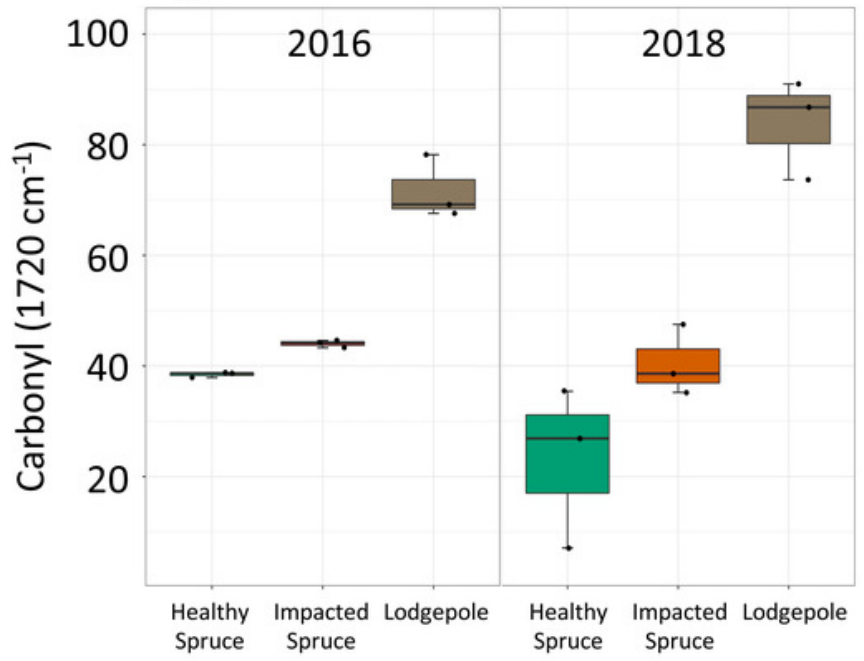


Figure 3

Gas flux as a function of season and needle decomposition.

$(A, B)$ Measured carbon dioxide above needle collars and $(C, D)$ on-site soil moisture and temperature during the sampling events of 2017 (A,C) and 2018 (B,D). The gas flux error bars indicate plus or minus one standard deviation ( $n=3$ or 4$)$. The soil temperature and moisture error bars indicate plus or minus one standard deviation of the hourly values collected during each sampling period. Soil temperature and moisture values are not available for the final date in October 2018.

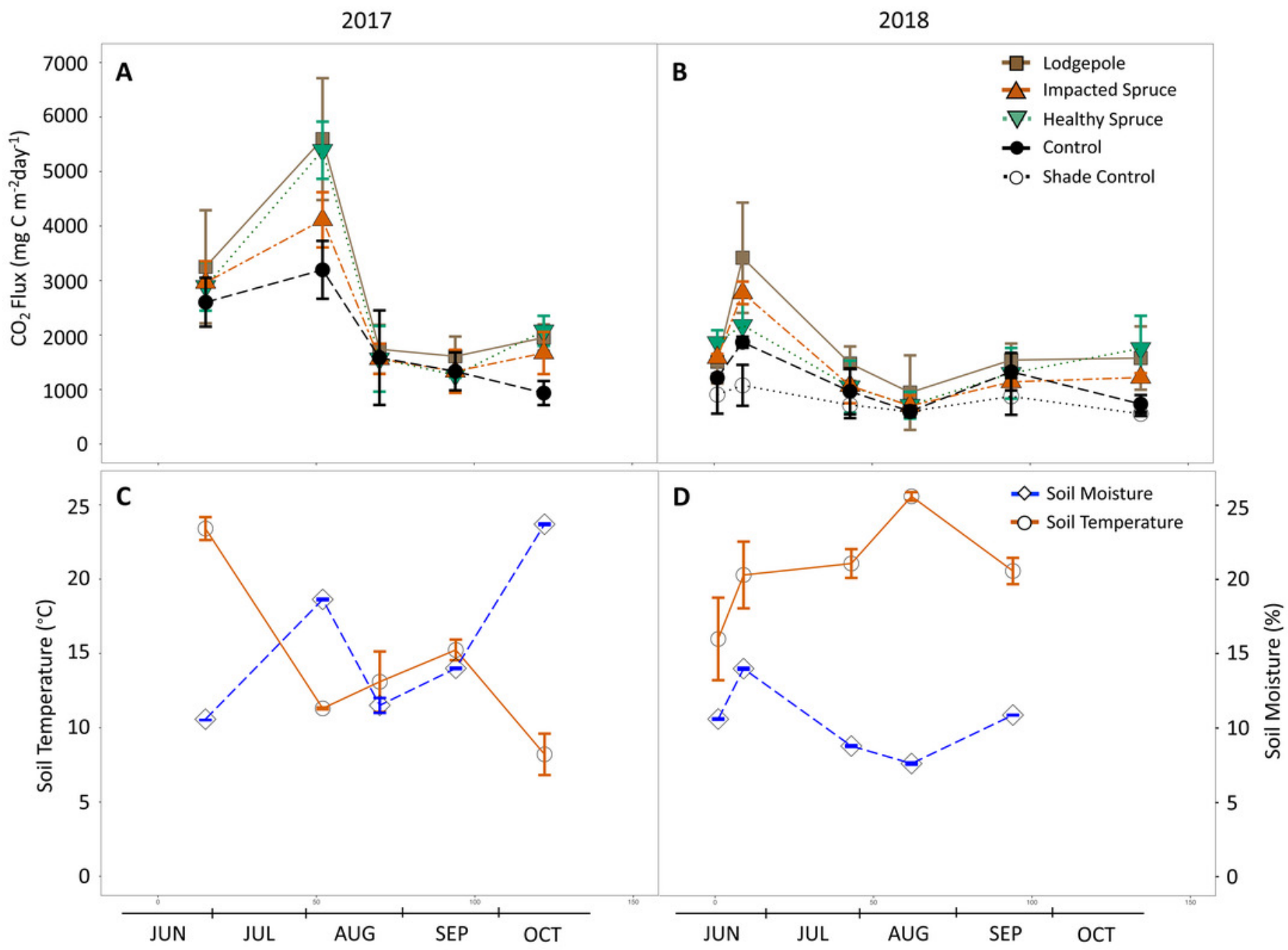




\section{Figure 4}

Needle decomposition shifts bacterial and fungal communities during wet seasons.

$(A, B)$ Bacterial and $(C, D)$ fungal communities significantly cluster based on needle type during the high moisture event of August $2017(\mathrm{~A}, \mathrm{C})$, and after a high moisture event in July 2018 (B,D) using the weighted UniFrac distance metric. Fungal communities under the spruce samples were grouped together in the July 2018 analysis due to low sample count. P and $R^{2}$ values for each figure are shown.
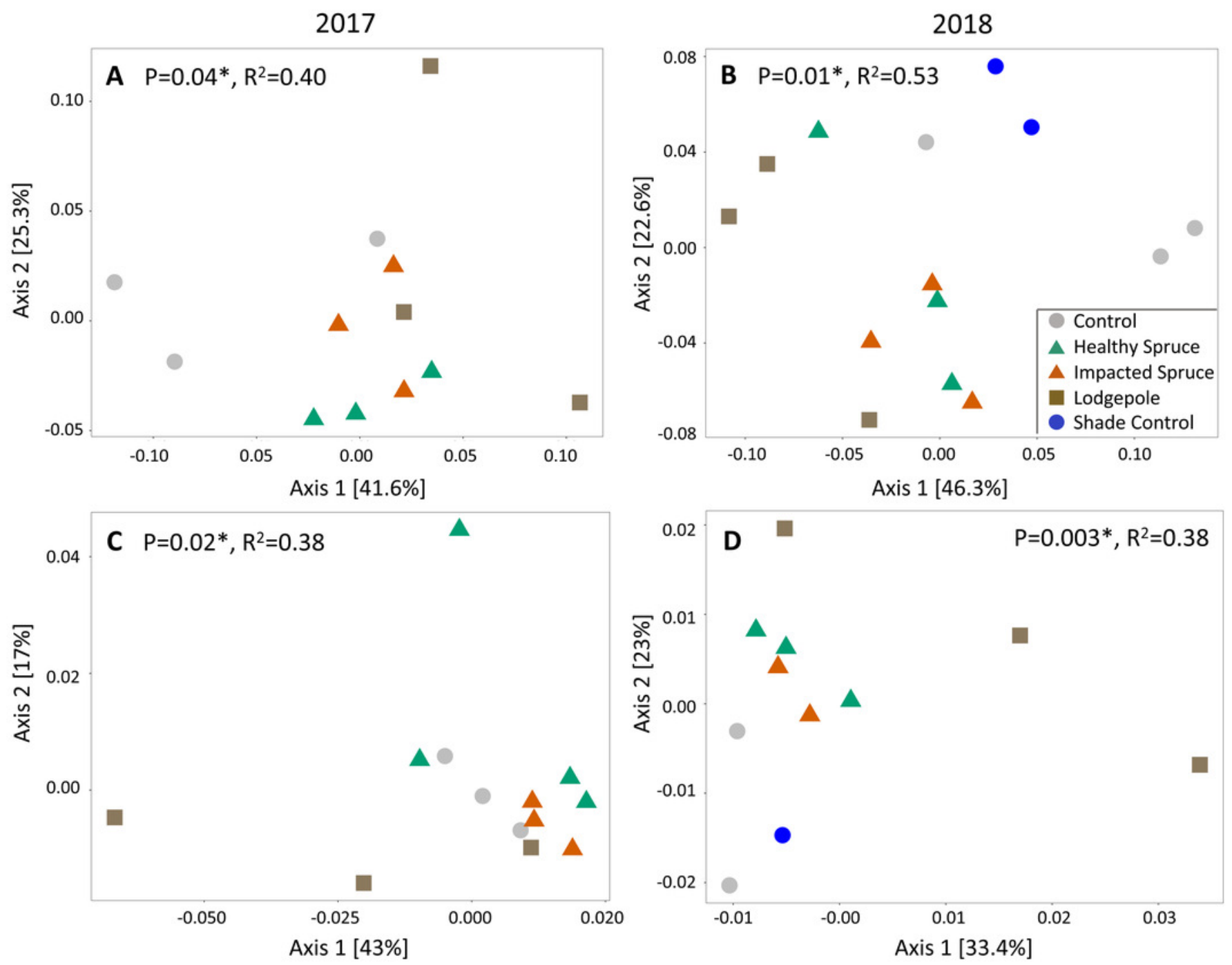


\section{Figure 5}

Top 15 most abundant bacterial genera differ as a function of sample type.

Top 15 genera in (A) August 2017 and (B) July 2018. Numeric values within each box represent the percent read abundance. Spruce values are binned healthy and impacted spruce $(n=6)$. Control in July 2018 is binned shaded and non-shaded $(n=5)$. Mean abundance values are shown within each heatmap box with color representing numerical ranges visually with low values in blue and high values in red. Symbols indicate significant differences determined by differential abundance analysis as follows: ^Significant difference between lodgepole and controls, "Significant difference between impacted spruce and controls, "Significant difference between the binned impacted and healthy spruce from the controls. 


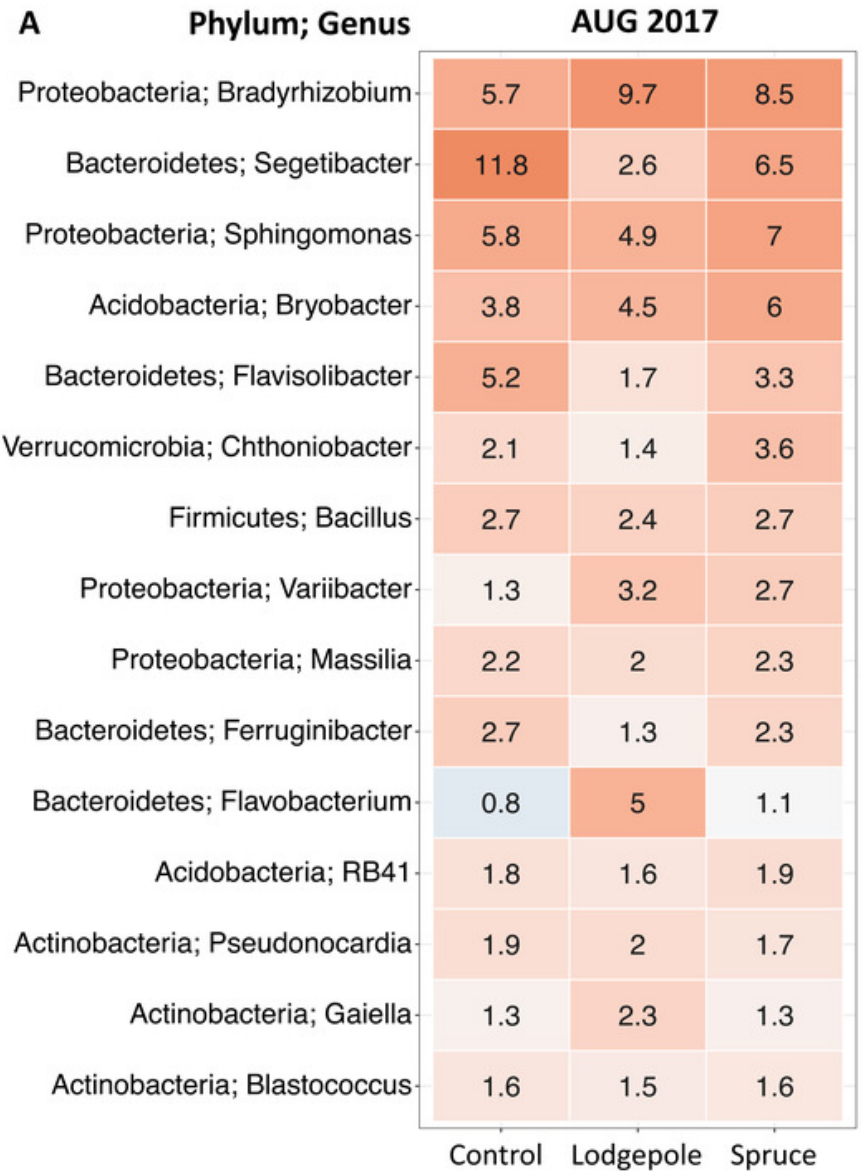

\begin{tabular}{|c|c|c|c|}
\hline Phylum; Genus & \multicolumn{3}{|c|}{ JUL 2018} \\
\hline Proteobacteria; Bradyrhizobium & 3.6 & 8.1 & 6.8 \\
\hline Acidobacteria; Bryobacter & 6.1 & 7 & 4.5 \\
\hline Bacteroidetes; Segetibacter & 10.2 & 0.8 & 2.7 \\
\hline Proteobacteria; Sphingomonas & 4.6 & 3.6 & 4.1 \\
\hline Firmicutes; Bacillus & 3.7 & 3.3 & 2.7 \\
\hline Proteobacteria; Massilia & 2.6 & 1 & 3.1 \\
\hline Bacteroidetes; Flavisolibacter & 4.4 & 0.8 & 1.4 \\
\hline Proteobacteria; Variibacter & 1.3 & 3.5 & 2 \\
\hline Actinobacteria; Pseudarthrobacter & 3.2 & 1 & 1.7 \\
\hline Verrucomicrobia; Chthoniobacter & 1.2 & 1.6 & 3 \\
\hline Actinobacteria; Blastococcus & 2.4 & 1.5 & 2 \\
\hline Acidobacteria; RB41. & 2.2 & 1.2 & 2.1 \\
\hline Actinobacteria; Nocardioides & 2.2 & 1.2 & 2 \\
\hline Actinobacteria; Pseudonocardia & 2.1 & 1.2 & 1.8 \\
\hline Bacteroidetes; Ferruginibacter & 1.8 & 0.6 & 1.6 \\
\hline
\end{tabular}




\section{Table $\mathbf{1}$ (on next page)}

Deionized water extractable nutrients as a function of needle type for harvested needles. 


\begin{tabular}{|rccc|}
\hline & $\begin{array}{c}\text { DOC } \\
(\mathrm{mg}-\mathrm{C} / \mathrm{g} \text { dry litter })\end{array}$ & $\begin{array}{c}\text { TN } \\
(\mathrm{mg}-\mathrm{N} / \mathrm{g} \text { dry litter })\end{array}$ & $\begin{array}{c}\text { SUVA } \\
\text { (g dry litter/mg-m) }\end{array}$ \\
\hline Impacted Spruce & $3.79( \pm 0.34)$ & $0.049( \pm 0.003)$ & $84( \pm 2)$ \\
Healthy Spruce & $2.29( \pm 0.15)$ & $0.041( \pm 0.001)$ & $130( \pm 6)$ \\
Lodgepole & $2.16( \pm 0.48)$ & $0.021( \pm 0.002)$ & $146( \pm 28)$ \\
\hline
\end{tabular}

2 Results are normalized based on an air-dried mass basis.

3 Each parameter averaged across triplicates $(n=3)$.

4 Standard deviation shown in parenthesis.

5 
Table 2 (on next page)

Porewater results from four sampling events in 2017-2018. 


\begin{tabular}{|r|ccc|ccc|}
\hline \multicolumn{7}{|c}{ June 2017 } \\
\hline & $\begin{array}{c}\text { DOC } \\
(\mathrm{mg} / \mathrm{L})\end{array}$ & $\begin{array}{c}\mathrm{TN} \\
(\mathrm{mg} / \mathrm{L})\end{array}$ & $\begin{array}{c}\text { SUVA } \\
(\mathrm{L} / \mathrm{mg}-\mathrm{m})\end{array}$ & $\begin{array}{c}\text { DOC } \\
(\mathrm{mg} / \mathrm{L})\end{array}$ & $\begin{array}{c}\text { TN } \\
(\mathrm{mg} / \mathrm{L})\end{array}$ & $\begin{array}{c}\text { SUVA } \\
(\mathrm{L} / \mathrm{mg}-\mathrm{m})\end{array}$ \\
Impacted Spruce & $5.3( \pm 1.4)$ & $0.49( \pm 0.19)$ & $2.2( \pm 0.8)$ & $6.6( \pm 2.1)$ & $\mathrm{BDL}$ & $3.0( \pm 0.8)$ \\
Healthy Spruce & $9.3( \pm 5.1)$ & $0.67( \pm 0.29)$ & $2.4( \pm 1.0)$ & $9.4( \pm 3.1)$ & $\mathrm{BDL}$ & $4.8( \pm 4.4)$ \\
Lodgepole & $4.3( \pm 1.1)$ & $0.38( \pm 0.14)$ & $2.1( \pm 0.9)$ & $10.3( \pm 3.3)$ & $0.32( \pm 0.30)$ & $3.7( \pm 0.8)$ \\
Control & $4.9( \pm 2.1)$ & $0.50( \pm 0.21)$ & $2.5( \pm 1.2)$ & $6.3( \pm 1.8)$ & $\mathrm{BDL}$ & $3.8( \pm 0.6)$ \\
\hline & \multicolumn{3}{c}{ October 2017 } & TN & October 2018 & \\
\hline & $\mathrm{DOC}$ & $(\mathrm{mg} / \mathrm{L})$ & $(\mathrm{L} / \mathrm{mg}-\mathrm{m})$ & $(\mathrm{mg} / \mathrm{L})$ & $(\mathrm{mg} / \mathrm{L})$ & $(\mathrm{L} / \mathrm{mg}-\mathrm{m})$ \\
Impacted Spruce & $6.7( \pm 2.3)$ & $0.38( \pm 0.12)$ & $1.85( \pm 0.87)$ & $9.4-$ & $0.57-$ & $2.1-$ \\
Healthy Spruce & $14.9( \pm 6.2)$ & $0.79( \pm 0.29)$ & $2.10( \pm 0.99)$ & $14.1( \pm 3.0)$ & $0.92( \pm 0.29)$ & $2.4( \pm 0.6)$ \\
Lodgepole & $12.4( \pm 3.4)$ & $0.63( \pm 0.24)$ & $1.78( \pm 0.54)$ & $16.8( \pm 5.9)$ & $0.76( \pm 0.10)$ & $4.3-$ \\
Control & $11.8( \pm 2.0)$ & $0.68( \pm 0.04)$ & $1.84( \pm 0.60)$ & $13.0-$ & $0.958-$ & - \\
\hline
\end{tabular}

1 Each parameter was averaged across two consecutive days of sampling to increase sample size.

2 Standard deviation shown in parenthesis.

$3 \mathrm{BDL}=$ below detection limits.

4

5 
Table 3 (on next page)

Soil extractions from sacrificed single collars in October 2017. 


\begin{tabular}{|rcccccccc|}
\hline & $\begin{array}{c}\mathrm{DOC} \\
(\mathrm{mg} / \mathrm{kg})\end{array}$ & $\begin{array}{c}\mathrm{TN} \\
(\mathrm{mg} / \mathrm{kg})\end{array}$ & $\begin{array}{c}\mathrm{NO}_{2}-\mathrm{N} \\
(\mathrm{mg} / \mathrm{kg})\end{array}$ & $\begin{array}{c}\mathrm{NO}_{3}-\mathrm{N} \\
(\mathrm{mg} / \mathrm{kg})\end{array}$ & $\begin{array}{c}\mathrm{NH}_{4}-\mathrm{N} \\
(\mathrm{mg} / \mathrm{kg})\end{array}$ & $\begin{array}{c}\mathrm{TON}-\mathrm{N} \\
(\mathrm{mg} / \mathrm{kg})\end{array}$ & $\begin{array}{c}\mathrm{SUVA} \\
(\mathrm{kg} / \mathrm{mg}-\mathrm{m})\end{array}$ & $\mathrm{pH}$ \\
\hline Impacted Spruce & 63.0 & 7.63 & 0.10 & 2.41 & 0.10 & 5.02 & 0.52 & 6.04 \\
Healthy Spruce & 57.5 & 4.08 & 0.06 & 0.07 & $\mathrm{BDL}$ & 3.96 & - & 6.37 \\
Lodgepole & 167.2 & 5.86 & 0.08 & 0.18 & $\mathrm{BDL}$ & 5.60 & 0.66 & 6.02 \\
Control & 41.7 & 8.81 & 0.10 & 4.19 & 0.12 & 4.40 & 0.43 & 6.61 \\
\hline
\end{tabular}

1 Results are normalized based on an air-dried mass basis.

2 Soil samples were collected from a single collar for each sample type $(n=1)$. 